\title{
Avaliação do potencial antioxidante e extração subcrítica do óleo de linhaça
}

\author{
Evaluation of the antioxidant potential and sub-critical extraction of linseed oil
}

Elisângela Lopes GALVÃO ${ }^{1 \star}$, Débora Cristina Fernandes da SILVA², Jamile Oliveira da SILVA², Ana Vládia Bandeira MOREIRA², Elisa Maria Bittencourt Dutra de SOUSA ${ }^{1}$

\section{Resumo}

As sementes de linhaça são ricas em ácidos graxos essenciais, fibras e compostos fenólicos, que exercem atividade antioxidante. O presente trabalho propôs a obtenção do óleo de linhaça a partir de diferentes métodos de extração (solvente orgânico e com $\mathrm{CO}_{2}$ subcrítico), a observação da presença de compostos com potencial antioxidante nas sementes, utilizando a Cromatografia em Camada Delgada (CCD) e ainda, a avaliação da efetividade através da co-oxidação de substratos do sistema $\beta$-caroteno/ácido linoléico. Para a CCD, foram utilizados os reveladores $\beta$-caroteno/ácido linoléico e cloreto férrico/ferricianeto de potássio. Para a atividade antioxidante foram feitas medidas espectrofotométricas de soluções contendo o sistema oxidante $\beta$-caroteno/ácido linoléico, com leituras a cada 15 minutos/2 horas. Em todos os extratos evidenciou-se a presença de compostos fenólicos antioxidantes, contudo, o extrato aquoso apresentou melhor atividade antioxidante nos volumes de 100 e $200 \mu \mathrm{L}$. O processo que apresentou maior rendimento foi a extração com Solvente Orgânico (SO), com o éter etílico como solvente $(25,89 \%)$.

Palavras-chave: linhaça; métodos de extração; atividade antioxidante; $\beta$-caroteno.

\begin{abstract}
Linseeds are rich in essential fatty acids, fibers and phenolic compounds, which have antioxidant activity. $\mathbb{Q}$ is work proposed obtaining linseed oil through di冈erent extraction methods (organic solvent and sub-critical $\mathrm{CO}_{2}$ ), observing the presence of compounds with antioxidant potential in the seeds through $\nabla$ in-Layer Chromatography (TLC) and evaluating the co-oxidation of substrates of the $\beta$-carotene/linoleic acid system. For TLC, the detection reagents $\beta$-carotene/linoleic acid and ferric chloride/potassium ferricyanide were used. For antioxidant activity, spectrophotometric measurements of solutions containing the oxidant system $\beta$-carotene/linoleic acid were made, with readings every 15 minutes/ 2 hours. $\otimes$ e presence of phenolic antioxidant compounds was evidenced in all extracts; however, the aqueous extract presented greater antioxidant activity in the volumes of 100 and $200 \mu \mathrm{L}$. $\nabla$ e highest extraction yield was obtained through organic solvent extraction, with ethyl ether as solvent (25.89\%).

Keywords: linseed; extraction methods; antioxidant activity; $\beta$-carotene.
\end{abstract}

\section{Introdução}

O crescente mercado dos produtos naturais, aliado ao interesse dos consumidores na prevenção de doenças, tem pressionado a indústria alimentícia na busca por produtos mais saudáveis e direcionado pesquisas nesse sentido. Neste contexto, os alimentos funcionais ganharam destaque pelos efeitos benéficos que promovem à saúde (ANJO, 2004).

Dentre os alimentos funcionais, a linhaça (Linum usitatissimum L.) é reconhecidamente uma das maiores fontes dos ácidos graxos essenciais $\omega$-3 e $\omega$ - 6 , possuindo ainda vários nutrientes como as fibras e os compostos fenólicos, conhecidos por exercerem atividade antioxidante (MAYES, 1994).

Para a evolução da indústria alimentícia, o processamento e a conseqüente necessidade de preservação dos alimentos estão intimamente relacionados com o incremento da procura de compostos com propriedades antioxidantes que aumentem o tempo de estocagem dos alimentos, reduzam as perdas nutricio- nais e que permitam o uso de óleos e gorduras mais suscetíveis à oxidação (BERNARDO-GIL; RIBEIRO; ESQUÍVEL, 2002). Uma vez que a utilização segura de antioxidantes sintéticos como o butil hidroxitolueno (BHT) tem sido questionada, (devido a problemas de solubilidade, aparecimento de sabores estranhos e caráter toxicológico), a investigação da presença de compostos com potencial antioxidante em alimentos como a linhaça desponta como uma alternativa natural contra os efeitos oxidativos dos radicais livres sobre os alimentos.

Aliada a isso, a obtenção do óleo da linhaça também é importante. Para tal finalidade são utilizadas técnicas específicas. A extração por solvente orgânico é a mais comumente utilizada para extrair lipídios do óleo de sementes, com um inconveniente: a possibilidade de ocorrer a degradação térmica dos ácidos graxos poliinsaturados, dependendo das condições utilizadas na extração convencional, além da necessidade de eliminação

Recebido para publicação em 28/2/2007

Aceito para publicação em 26/9/2007 (002301)

${ }^{1}$ Departamento de Engenharia Química - DEQ, Centro de Tecnologia - CT, Universidade Federal do Rio Grande de Norte - UFRN, Campus Universitário, s/n, CEP 59072-970, Natal - RN, Brasil, Email: elgalvao@eq.ufrn.br

2 Departamento de Nutrição, Centro de Ciências da Saúde - CCS, Universidade Federal do Rio Grande de Norte - UFRN, Av. Gen. Cordeiro de Farias, s/n., Petrópolis, CEP 59010-180, Natal-RN, Brasil,Email:ana.vladia@terra.com.br

${ }^{*}$ A quem a correspondência deve ser enviada 
dos resíduos de solvente orgânico do óleo (BOZAN; TEMELLI, 2002). A extração com fluidos pressurizados, especialmente $\mathrm{CO}_{2}$, vem sendo aplicada com sucesso para a obtenção de diversos óleos essenciais e vegetais (BOZAN; TEMELLI, 2002; CARLSON et al., 2001; DEL VALLE et al., 2000; ESQUÍVEL; BERNARDO-GIL; KING, 1999; KOPCAK; AZEVEDO; MOHAMED, 2004; OZER et al., 1996; SOUSA et al., 2005; SOUSA et al., 2002; SOVOVÁ et al., 1994), com a vantagem da obtenção de produtos livres de solvente, uma vez que a separação entre soluto e solvente se dá pela alteração das condições de pressão e/ou temperatura, de modo que o solvente utilizado esteja gasoso nessas condições. Além disso, este método é indicado quando existe perigo de degradação térmica dos extratos, já que seu controle operacional possibilita a utilização de temperaturas moderadas. Desse modo, o presente trabalho propôs a comparação das técnicas citadas (extração com solvente e com $\mathrm{CO}_{2}$ pressurizado) na obtenção do óleo de linhaça com o intuito de observar questões como rendimento do processo e características do produto; a observação do potencial antioxidante da semente obtido através da Cromatografia em Camada Delgada (CCD) e a avaliação da efetividade através da co-oxidação de substratos do sistema $\beta$-caroteno/ácido linoléico.

\subsection{Linhaça}

A linhaça (Linum usitatissimum L.) é a semente do linho, planta pertencente à família das Lináceas, que tem sido cultivada há cerca de 4000 anos nos países mediterrâneos. É uma semente com várias aplicações, podendo ser usada como matéria-prima para produção de óleo e farelo. O óleo é usado pelas indústrias na fabricação de tintas, vernizes e resinas, já o farelo é vendido para fábricas de rações animais. Também estão em desenvolvimento processos que incluem o óleo de linhaça em rações, de forma que os produtos para consumo humano como a carne, ovos, leite, possam estar enriquecidos com ácidos graxos $\omega 3$ (TURATTI, 2001). As sementes também são utilizadas como complemento alimentar, sendo adicionadas a pães, bolos e biscoitos ou ainda misturadas cruas aos alimentos.

Principais componentes da linhaça: é uma excelente fonte de fibras. Possui tanto fibras solúveis quanto insolúveis (NORTHRUP, 2004). Rica em ácidos graxos essenciais, com elevado teor de lipídios (32 a 38\%), sendo que destes 50 a 55\% são do ácido graxo insaturado $\alpha$-linolênico (18:3n-3), pertencente à família $\omega 3$ (GÓMEZ, 2003). Contém ainda ácido linoléico (da família $\omega 6$ ) e ácidos graxos monoinsaturados e saturados.

\subsection{Antioxidantes}

São substâncias capazes de prevenir os efeitos deletérios da oxidação pela inibição da lipoperoxidação, seqüestro de radicais livres e/ou quelação de íons metálicos. Os antioxidantes podem ser divididos em duas classes: os com atividade enzimática e os sem atividade. No primeiro grupo estão os compostos capazes de bloquear a iniciação da oxidação, ou seja, as enzimas que removem as espécies reativas ao oxigênio. No segundo grupo estão as moléculas que interagem com as espécies radicalares e são consumidas durante a reação. Neste grupo incluem-se os antioxidantes naturais, como os compostos fenólicos (MOREIRA; MANCINI FILHO, 2003).
Os compostos fenólicos presentes em óleos de sementes possuem fortes propriedades antioxidantes e quando usados junto com ingredientes de alimentos processados contendo lípides podem exercer um efeito positivo na redução da oxidação lipídica (MOREIRA, 1999), podendo agir ainda como redutores de oxigênio singleto e atuar na quelação de metais (DUARTE-ALMEIDA et al., 2006).

Dentre as técnicas utilizadas para a determinação da atividade antioxidante in vitro, a que utiliza o sistema $\beta$-caroteno/ ácido linoléico está presente em diversos estudos. Tal método avalia a atividade de inibição de radicais livres gerados durante a peroxidação do ácido linoléico e está fundamentado em medidas espectrofotométricas da descoloração (oxidação) do $\beta$-caroteno induzida pelos produtos de degradação oxidativa do ácido linoléico. Este método determina a atividade de uma amostra ou composto de proteger um substrato lipídico da oxidação (DUARTE-ALMEIDA et al., 2006).

\section{Material e métodos}

\subsection{Preparo das amostras}

Para a realização dos procedimentos experimentais foram utilizadas sementes de linhaça (Linum usitatissimum L.) do tipo marrom, coletadas em três supermercados de Natal-RN. As amostras foram homogeneizadas e armazenadas em frascos.

A semente foi posteriormente triturada em multiprocessador doméstico (ARNO, modelo PRO, Brasil) e amostras de $165 \mathrm{~g}$ (capacidade da coluna extratora) foram preparadas para a obtenção do óleo por $\mathrm{CO}_{2}$ pressurizado.

Para a obtenção dos extratos, a semente triturada foi peneirada em peneiras da série Tyler e a granulometria de 20 mesh foi utilizada.

\subsection{Obtenção dos extratos}

Duas técnicas diferentes de extração com solvente orgânico foram empregadas para a obtenção dos extratos. Os testes foram realizados para dois tipos de solvente: éter etílico (CRQ- 97-98\% de pureza) e etanol (VETEC-99,5\% de pureza).

Solvente orgânico sob baixa temperatura (SO): A metodologia empregada foi descrita por Povh (2000) e modificada por Galvão (2004) e pode ser dividida em três etapas: incubação da amostra, filtração a vácuo e evaporação do solvente. A amostra (30 g de linhaça marrom na granulometria de 20 mesh $+180 \mathrm{~mL}$ de solvente éter etílico ou etanol) foi incubada a $15^{\circ} \mathrm{C}$ sob agitação de $190 \mathrm{rpm}$ por 8 horas. Seguiu-se a filtração em bomba de vácuo, onde o extrato (filtrado) foi separado da matriz sólida (resíduo), pesado e colocado para evaporar em placas de Petri num ambiente a $20{ }^{\circ} \mathrm{C}$. Após a completa evaporação do solvente, as placas foram pesadas e o rendimento da extração foi calculado. O rendimento total do extrato foi calculado a partir da razão entre a massa total de extrato no filtrado e a massa inicial de linhaça moída utilizada.

Extração seqüencial (SE): Uma extração seqüencial foi utilizada para a obtenção dos extratos etéreo (baixa polaridade), 
alcoólico (polaridade intermediária) e aquoso (alta polaridade). Com os extratos foram conduzidas as análises cromatográficas e de atividade antioxidante. As etapas da extração encontram-se esquematizadas na Figura 1.

A partir dos extratos obtidos na extração seqüencial foram realizadas análises para identificação dos compostos fenólicos através da técnica $\mathrm{CCD}$, determinação das atividades antioxidantes dos extratos no sistema $\beta$-caroteno/ácido linoléico e ainda um estudo cinético da Atividade Antioxidante (AA).

\subsection{Obtenção do óleo}

Para a obtenção do óleo de linhaça, foi utilizado um extrator de leito fixo (esquematizado na Figura 2) desenvolvido por Sousa

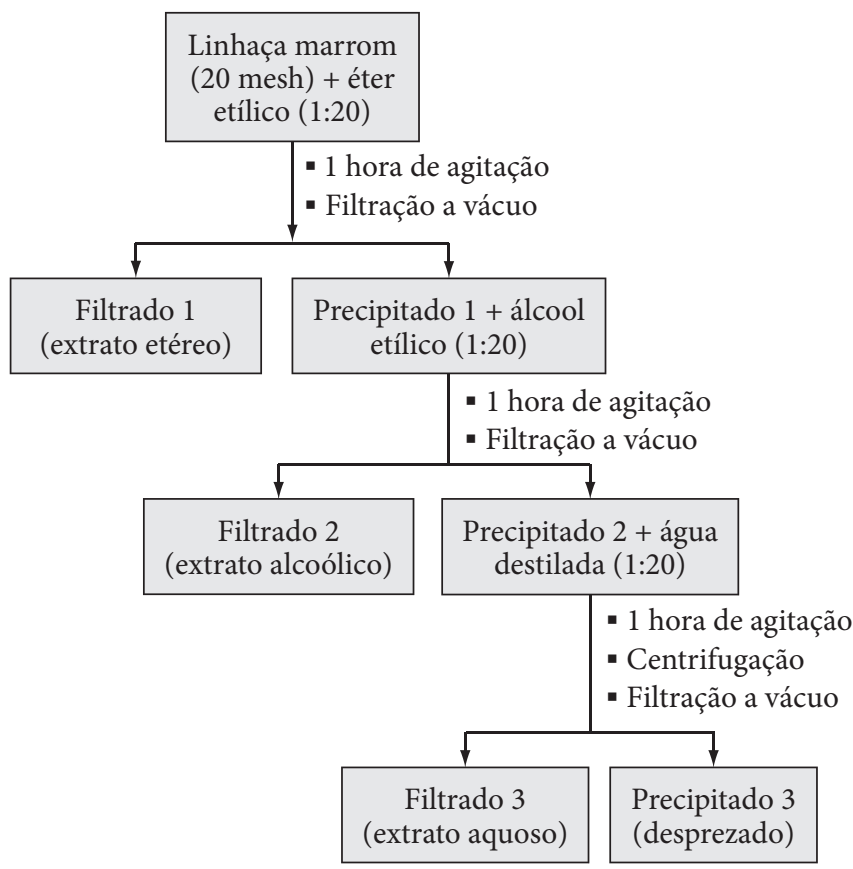

Figura 1. Etapas seqüenciais de preparação dos extratos etéreo, alcoólico e aquoso.

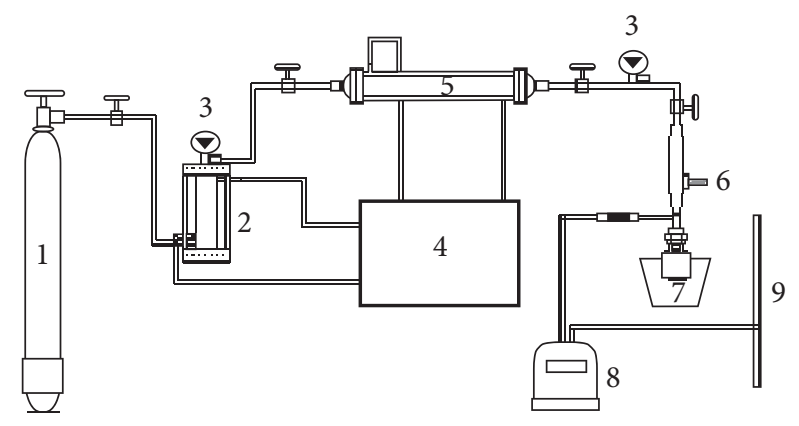

Figura 2. Esquema do extrator. 1 = cilindro sifonado de $\mathrm{CO}_{2}$ com capacidade de $25 \mathrm{~kg} ; 2$ tanque pulmão com capacidade de $0.5 \times 10^{-3} \mathrm{~m}^{3}$, responsável por ajustar a temperatura do solvente às condições operacionais; 3 = manômetros do tipo Bourdon; 4 = banho termostático; $5=$ coluna extratora de tubo duplo $(0,6 \mathrm{~m}$ de comprimento, $0,0216 \mathrm{~m}$ de diâmetro e $0,0028 \mathrm{~m}$ de espessura de parede); 6 = válvula micrométrica com fita de aquecimento; 7 = frasco de vidro com capacidade para $5 \mathrm{~mL}$ envolvido por recipiente contendo gelo e água; $8=$ totalizador de vazão; e 9 = bolhômetro de vidro para aferição da vazão.
(2001), operando com o solvente $\mathrm{CO}_{2}$ em condições subcríticas $\left(\mathrm{P}=7 \mathrm{MPa}\right.$ e $\left.\mathrm{T}=25^{\circ} \mathrm{C}\right)$ a uma vazão de $1,5 \mathrm{~g} \mathrm{CO}_{2} /$ minuto. $\mathrm{O}$ tempo de extração foi fixado em 4 horas. O leito fixo foi composto por cerca de $165 \mathrm{~g}$ da amostra empacotados na coluna extratora juntamente com $40 \mathrm{~mL}$ de co-solvente. Os co-solventes escolhidos foram o etanol e o isopropanol. Tal escolha foi feita baseando-se na polaridade destas substâncias, bem como na facilidade com que se poderia isolar o soluto (óleo) extraído, isto é, no baixo ponto de ebulição do solvente para sua posterior evaporação. O óleo extraído foi armazenado em frascos de vidro âmbar e estes estocados em freezer doméstico para análises posteriores.

A condição subcrítica foi adotada devido às limitações do equipamento, e a utilização de co-solventes foi proposta, uma vez que testes preliminares sem o uso de co-solventes resultaram em rendimentos desprezíveis.

\subsection{Identificação dos compostos fenólicos por CCD}

Para a separação dos compostos fenólicos dos extratos foi utilizada a técnica de Izmailov e Shraiber (1938), com condições padronizadas e descritas por Moreira (1999). Nos ensaios foram utilizadas alíquotas de $10 \mu \mathrm{L}$ de cada tipo de extrato (etéreo, alcoólico e aquoso). Na revelação das placas, foram usados os reagentes cromatográficos em spray descritos nos procedimentos metodológicos por Duve e White (1991). Segundo tais autores, a solução de $\beta$-caroteno reage com as substâncias antioxidantes, resultando numa coloração laranja, enquanto a solução de ferricianeto de potássio/cloreto férrico reage com os compostos fenólicos, resultando numa coloração azul.

\subsection{Atividade antioxidante no sistema $\beta$-caroteno/ácido linoléico}

A Atividade Antioxidante (AA) foi determinada pelo método in vitro, desenvolvido por Marco (1968) e modificado por Miller (1971), empregando-se o ácido linoléico, Tween 20 e $\beta$-caroteno. Esse sistema foi mantido a aproximadamente $50^{\circ} \mathrm{C}$, e medidas espectrofotométricas de absorbância foram feitas em espectrofotômetro, modelo Spectrophotometer Coleman 395-D Digital UV-VIS, a $470 \eta \mathrm{m}$, a cada 15 minutos, durante 2 horas. A partir destes dados foi realizado um estudo do comportamento cinético da linhaça comparada ao antioxidante sintético BHT. Esse estudo é importante por permitir a visualização da reação de inibição da oxidação no sistema $\beta$-caroteno/ácido linoléico.

\subsection{Estudo cinético da atividade antioxidante (AA)}

A eficiência da atividade antioxidante dos extratos foi estimada pelo método das tangentes em duas partes das curvas cinéticas, segundo modificação do método feita por Moreira (1999) e descrito por Yanishilieva e Marinova (1995). Na primeira parte da curva (entre 15 e 45 minutos após o início da reação) foi medida a eficiência do antioxidante de bloquear a reação em cadeia através da interação com os radicais peróxido. Essa eficiência é medida pela relação entre as tangentes das curvas cinéticas, apresentadas pelos meios contendo o extrato e o controle (sem antioxidante). Os valores obtidos foram denominados fator 1 (F1). Na segunda parte da curva (entre 75 e 105 minutos após 
o início da reação) foi medida a possibilidade do antioxidante participar de outras reações durante o processo oxidativo. Essa medida é obtida pela relação entre as tangentes das curvas cinéticas apresentadas pelo meio contendo o extrato e o controle sem antioxidante. Os valores encontrados foram denominados de fator 2 (F2). Os resultados obtidos referentes à F1 e F2 podem apresentar valores maiores ou menores que 1 . Se o resultado for superior a 1, então o antioxidante passa a exercer um efeito contrário, ou seja, pró-oxidante (PO), contribuindo para as reações oxidativas.

\section{Resultados e discussão}

\subsection{Avaliação dos métodos de extração}

O rendimento de cada processo de extração avaliado encontra-se listado na Tabela 1.

Os maiores rendimentos foram observados para a extração do tipo (SO), com destaque para o ensaio que empregou éter etílico como solvente $(25,89 \%)$. A mesma técnica empregando etanol como solvente apresentou um rendimento de 6,09\%. Tal fato pode ser atribuído à capacidade que o éter possui de extrair, além de triacilglicerídeos, vitaminas, esteróides, resinas e pigmentos, sendo um solvente de extração mais ampla que o etanol (CECCHI, 1999).

As extrações com $\mathrm{CO}_{2}$ subcrítico $\left(\mathrm{CO}_{2} \mathrm{~s}\right)$ apresentaram rendimentos inferiores (1,61 e 4,84\%) aos obtidos para a técnica $\mathrm{SO}$. Os ensaios em que o isopropanol foi utilizado como cosolvente resultaram em rendimentos cerca de 3 vezes maiores $(4,84 \%)$ do que os ensaios em que o etanol foi o co-solvente empregado (1,61\%). Aparentemente o isopropanol solubilizou mais e/ou melhor os componentes do óleo da linhaça, no entanto, explicações conclusivas só poderão ser dadas a partir de análises detalhadas do óleo, o que não foi possível realizar para o presente trabalho. Quanto às características, o óleo obtido a partir da técnica $\mathrm{CO}_{2} \mathrm{~s}$, após a evaporação do co-solvente, apresentou-se mais claro e menos viscoso do que o obtido a partir do uso de solventes orgânicos.

Os ensaios em condições subcríticas foram realizados em caráter de teste, uma vez que o equipamento utilizado foi projetado para extração de óleos essenciais em condições amenas e não comportaria a condição supercrítica. No entanto, encontrase em fase de elaboração o projeto de um extrator supercrítico para obtenção de óleos vegetais, que será futuramente utilizado para obter o óleo de linhaça em condições supercríticas.

\subsection{Identificação dos compostos fenólicos pela CCD}

Todos os extratos da linhaça (etéreo, alcoólico e aquoso) apresentaram bandas reconhecidas com atividade antioxidan-

Tabela 1. Comparação das técnicas de extração a partir do rendimento do processo.

\begin{tabular}{ccc}
\hline Método de extração & \multicolumn{2}{c}{ Rendimento do processo (\%) } \\
\hline Solvente orgânico $(\mathrm{SO})$ & $25,89^{\mathrm{a}}$ & $6,09^{\mathrm{b}}$ \\
$\mathrm{CO}_{2}$ subcrítico $\left(\mathrm{CO}_{2} \mathrm{~s}\right)$ & $1,61^{\mathrm{c}}$ & $4,84^{\mathrm{d}}$ \\
\hline
\end{tabular}

a) Extração com éter etílico; b) extração com etanol; c) etanol como co-solvente; e d) isopropanol como co-solvente. te (revelação no sistema $\beta$-caroteno), conforme mostrado na Tabela 2.

Em relação ao sistema revelador ferricianeto/cloreto férrico, pôde-se constatar a presença de compostos fenólicos através da observação do comportamento da linhaça sobre a placa cromatográfica (Figura 3).

A placa cromatográfica revela informações importantes sobre as atividades antioxidantes pesquisadas, significando que as substâncias solubilizadas nos extratos da linhaça apresentam compostos fenólicos. Apesar do extrato aquoso ter apresentado melhor atividade antioxidante (AA), a análise da placa leva a constatar que os outros extratos também possuem tais compostos, mesmo com a evidência da menor AA, que pode ser conseqüência da influência do meio. A importância desta técnica está em demonstrar a presença dos compostos fenólicos antioxidantes apesar das adversidades do meio ao qual o extrato da linhaça foi submetido.

\subsection{Atividade antioxidante: sistema $\beta$-caroteno/ácido linoléico}

A atividade antioxidante (AA) ou pró-oxidante (PO) de fenólicos é dependente dos seguintes fatores: potencial de redução de metais, poder de quelação e pH. Trabalhos de laboratório evidenciam que as propriedades antioxidantes dos fenólicos são também dependentes das suas características de solubilidade (MOREIRA, 1999; MOREIRA; MANCINI FILHO, 2003).

A Figura 4 demonstra o percentual de atividade antioxidante correspondente a cada extrato (aquoso, alcoólico e etéreo) obtido a partir da semente.

Tabela 2. Fator de retenção (Rf) dos extratos da linhaça na CCD.

\begin{tabular}{cllc}
\hline Mancha & \multicolumn{1}{c}{ Revelação } & Cor & Rf \\
\hline A & $\beta$-caroteno/clorofórmio & Laranja & 0,90 \\
B & $\beta$-caroteno/clorofórmio & Laranja & 0,90 \\
C & $\beta$-caroteno/clorofórmio & Laranja & 0,80 \\
$A^{\prime}$ & Ferricianeto/cloreto férrico & Azul & 0,90 \\
B $^{\prime}$ & Ferricianeto/cloreto férrico & Azul & 0,90 \\
C' $^{\prime}$ & Ferricianeto/cloreto férrico & Azul & 0,80 \\
$D^{\prime}$ & Ferricianeto/cloreto férrico & Azul & 0,60 \\
\hline
\end{tabular}

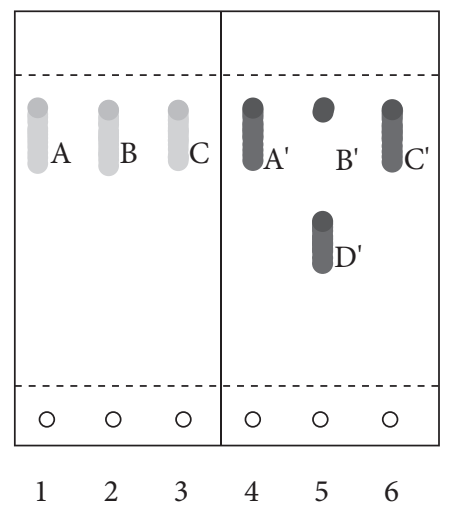

1-Extrato etéreo

2-Extrato alcoólico

3-Extrato aquoso

4-Extrato etéreo

5-Extrato alcoólico

6-Extrato aquoso

Figura 3. Cromatografia em Camada Delgada (CCD) dos extratos da linhaça. 


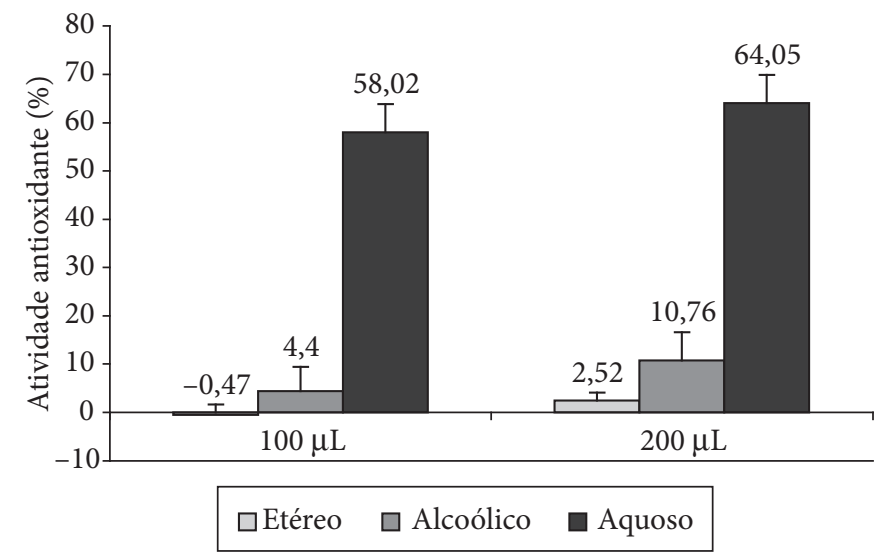

Figura 4. Porcentagem de inibição da oxidação, segundo o volume dos extratos etéreo, alcoólico e aquoso da linhaça no sistema $\beta$-caroteno/ ácido linoléico.

O extrato aquoso foi o que melhor solubilizou substâncias com princípios antioxidantes. Apresentou 58,02 e 64,05\% de inibição da oxidação nos volumes de 100 e $200 \mu \mathrm{L}$, respectivamente. É importante salientar a característica de solubilidade dos fenólicos presentes neste extrato, cujo caráter hidrofílico de tais substâncias melhora significativamente a resposta à oxidação (MOREIRA, 1999). Tal fato foi observado por Porter (1993), que descreveu o "paradoxo antioxidante" como um fenômeno no qual Seqüestradores de Radicais Livres (SRL) hidrofílicos são antioxidantes mais efetivos do que os SRL hidrofóbicos em emulsões de óleo.

Os percentuais de inibição da oxidação para os extratos etéreo $(-0,47$ em $100 \mu \mathrm{L}$ e $2,52 \mathrm{em} 200 \mu \mathrm{L})$ e alcoólico $(4,4$ e 10,76 para 100 e $200 \mu \mathrm{L}$, respectivamente) foram muito baixos. No entanto, apesar dos baixos percentuais, a técnica da CCD demonstra a existência de compostos fenólicos antioxidantes nestes extratos. Sua atividade antioxidante não pôde ser potencialmente demonstrada devido às características intrínsecas da semente em relação ao meio em que está solubilizada.

\subsection{Comportamento cinético}

As Figuras 5 e 6 demonstram o comportamento cinético dos extratos da linhaça em volumes de 100 e $200 \mu \mathrm{L}$ comparados às amostras do controle e do antioxidante sintético BHT.

A partir da análise das Figuras 5 e 6 é possível verificar que apenas o extrato aquoso apresentou comportamento de inibição da oxidação semelhante ao antioxidante sintético BHT (para a concentração de $10 \mathrm{ppm}$ ). Os fatores cinéticos F1 e F2 foram calculados com base nos dados das Figuras 5 e 6 e encontram-se expressos na Tabela 3.

Segundo Yanishilieva e Marinova (1995), o fator F1 representa a efetividade do antioxidante em bloquear as reações em cadeia, ocasionadas pelos radicais livres, ou seja, representa a capacidade de atuação do composto fenólico na etapa de iniciação da oxidação. Já o fator F2 apresentaria sua ação na fase de propagação, inferindo a possibilidade do antioxidante participar de reações como a decomposição de hidroperóxidos

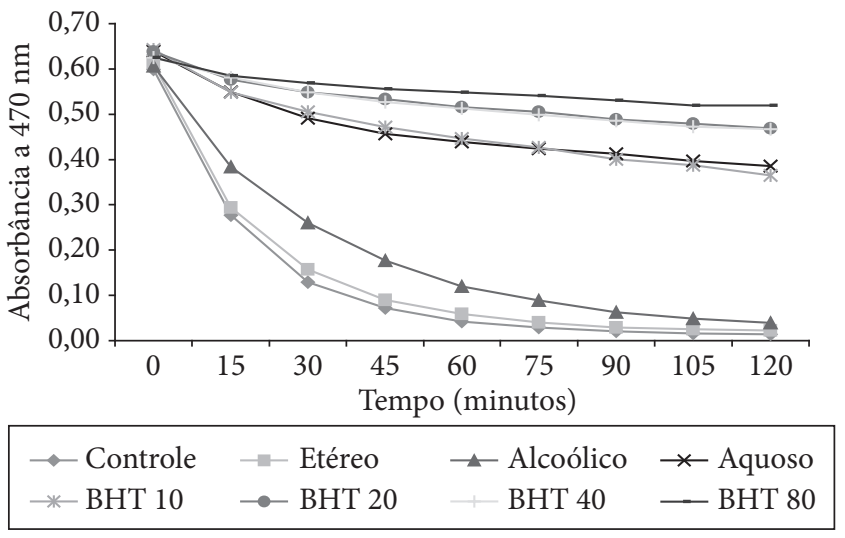

Figura 5. Atividade antioxidante dos extratos de linhaça marrom em volumes de $100 \mu \mathrm{L}$ em comparação aos volumes de 10, 20, 40 e $80 \mu \mathrm{L}$ de BHT.

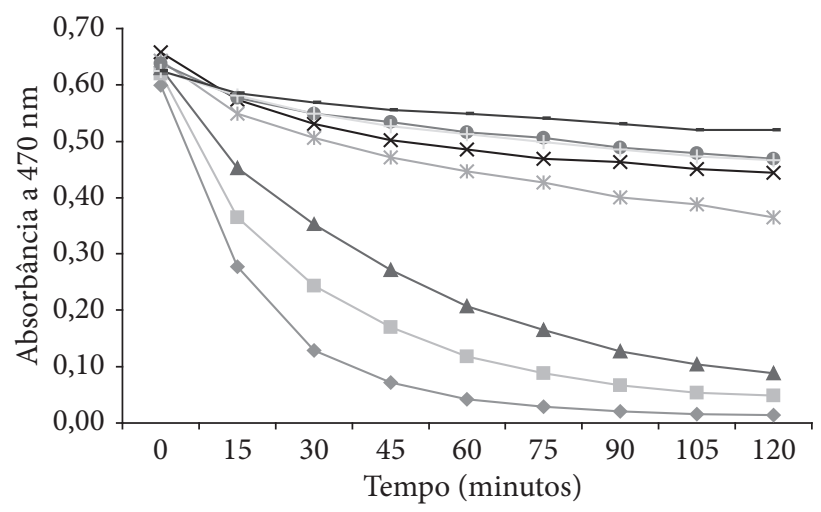

\begin{tabular}{|c|c|c|c|}
\hline $\begin{array}{l}\rightarrow \text { Controle } \\
- \text { BHT } 10\end{array}$ & $\begin{array}{l}- \text { Etéreo } \\
- \text { BHT } 20\end{array}$ & —- Alcoólico & $\begin{array}{l}* \text { Aquoso } \\
-- \text { BHT } 80\end{array}$ \\
\hline
\end{tabular}

Figura 6. Atividade antioxidante dos extratos da linhaça marrom em volumes de $200 \mu \mathrm{L}$ em comparação aos volumes de 10, 20, 40 e $80 \mu \mathrm{L}$ de BHT.

Tabela 3. Fatores cinéticos F1 e F2 caracterizando a inibição da oxidação do sistema $\beta$-caroteno/ácido linoléico pelo extrato da linhaça junto ao antioxidante BHT.

\begin{tabular}{ccccc}
\hline Antioxidante & \multicolumn{4}{c}{ Fatores } \\
\hline Extratos da linhaça & \multicolumn{2}{c}{$\mathrm{F} 1$} & \multicolumn{2}{c}{$\mathrm{F} 2$} \\
\cline { 2 - 6 } & $100 \mu \mathrm{L}$ & $200 \mu \mathrm{L}$ & $100 \mu \mathrm{L}$ & $200 \mu \mathrm{L}$ \\
\hline Etéreo & 0,99 & 0,95 & 1,15 & 2,62 \\
Alcoólico & 1,01 & 0,89 & 3,07 & 4,69 \\
Aquoso & 0,45 & 0,35 & 2,08 & 1,38 \\
BHT & \multicolumn{2}{c}{ F1 } & \multicolumn{2}{c}{ F2 } \\
$10 \mu \mathrm{L}$ & \multicolumn{2}{c}{0,38} & \multicolumn{2}{c}{0,43} \\
$20 \mu \mathrm{L}$ & \multicolumn{2}{c}{0,21} & \multicolumn{2}{c}{1,86} \\
$40 \mu \mathrm{L}$ & 0,27 & \multicolumn{2}{c}{1,29} \\
$80 \mu \mathrm{L}$ & 0,14 & \multicolumn{2}{c}{1,24} \\
\hline
\end{tabular}

que reagem com o oxigênio e aceleram o processo oxidativo. Quanto mais próximos de 1 estiverem os valores de F1 e F2, menor será a atividade antioxidante. 
A partir da análise dos fatores F1 e F2 mostrados na Tabela 3, observa-se um comportamento cinético antioxidante relevante no extrato aquoso das amostras, tanto em 100 quanto em $200 \mu \mathrm{L}$, significando que os compostos antioxidantes presentes são bons seqüestradores de radicais livres, capazes de bloquear a reação na etapa da iniciação. Para os extratos etéreo e alcoólico não foram obtidos bons percentuais de proteção antioxidante quando comparados ao BHT. Porém, através da cinética verifica-se que os compostos fenólicos ali presentes, apesar das interferências do meio e por demonstrarem valores de $\mathrm{F} 1<1$, possuem a capacidade de bloquear o início da reação de oxidação. Dessa forma, são classificados como sendo do tipo I, ou seja, bons bloqueadores de reações oxidativas (RIBÉREAU-GAYON, 1968).

\section{Conclusões}

Dentre os métodos de extração avaliados, o maior rendimento foi observado para a extração do tipo SO, com o éter etílico como solvente $(25,89 \%)$.

Todos os extratos da linhaça apresentaram atividade antioxidante e presença de compostos fenólicos, com destaque para o extrato aquoso, que apresentou bons percentuais de proteção contra a oxidação lipídica quando comparados ao BHT na concentração de $10 \mathrm{ppm}$, sendo um provável bom substituto dos antioxidantes sintéticos. É necessário, porém, uma maior investigação do potencial antioxidante da linhaça em outros meios de solubilidade, assim como estudos de concentração, visto que esse é um questionamento a ser esclarecido para maior suporte no uso desse alimento como substituto dos antioxidantes sintéticos.

\section{Agradecimentos}

Agradecemos aos colaboradores do Departamento de Nutrição da UFRN e ao CNPQ pelo suporte financeiro.

\section{Referências bibliográficas}

ANJO, D. F. C. Alimentos funcionais em angiologia e cirurgia vascular. Jornal Vascular Brasileiro, v. 3, n. 2. p. 145-154, 2004.

BERNARDO-GIL, M. G.; RIBEIRO, M. A.; ESQUÍVEL, M. M. Produção de extractos para a indústria alimentar: uso de fluidos supercríticos. Indústria Alimentar. Boletim de Biotecnologia, v. 73, p. 14-21, 2002. (in Portuguese).

BOZAN, B.; TEMELLI, F. Supercritical $\mathrm{CO}_{2}$ extraction of flaxseed. Journal of the American Oil Chemists' Society, Champaign, v. 79, n. 3, p. 231-235, 2002.

CARLSON, L. H. C. et al. Extraction of lemongrass essential oil with dense carbon dioxide. The Journal of Supercritical Fluids, New v. 21, n. 1, p. 33-39, 2001.

CECCHI, H. M. Fundamentos teóricos e práticos em análise de alimentos. Campinas: Editora da Unicamp, 1999.

DEL VALLE, J. M. et al. Comparison of conventional and supercritical $\mathrm{CO}_{2}$ - Extracted rosehip oil. Brazilian Journal of Chemical Engineering, v. 17, n. 3, p. 33-348, 2000.

DUARTE-ALMEIDA, J. M. et al. Avaliação da atividade antioxidante utilizando sistema $\beta$-caroteno/ácido linoléico e método de seqüestro de radicais DPPH. Ciência e Tecnologia de Alimentos, v. 26, n. 2, p. 446-452, abr./jun. 2006.
DUVE, K. J.; WHITE, P. J. Extraction and identification of antioxidants in oats. Journal of the American Oil Chemists' Society, v. 61, n. 6, p. 365-370, 1991.

ESQUÍVEL, M. M.; BERNARDO-GIL, M. G.; KING, M. B. Mathematical models for supercritical extraction of olive husk oil. The Journal of Supercritical Fluids, v. 16, n. 1, p. 43-58, 1999.

GALVÃO, E. L. Extração do óleo essencial de Cymbopogon winterianus J. com $\mathrm{CO}_{2}$ pressurizado. Natal, 2004. 99p. Dissertação - (Mestre em Engenharia Química), Departamento de Engenharia Química, Universidade Federal do Rio Grande do Norte - UFRN.

GÓMEZ, M. E. D. B. Modulação da composição de ácidos graxos poliinsaturados ômega 3 de ovos e tecidos de galinhas poedeiras, através da dieta. I. Estabilidade oxidativa. São Paulo, 2003. 149 p. Tese - (Doutorado em Ciência dos Alimentos), Faculdade de Ciências Farmacêuticas, Universidade de São Paulo - USP.

IZMAILOV, N. A.; SHRAIBER, M. S. A drop-chromatographic method of analysis and its utilization in pharmacy. Farmatsiya, Moscow, v. 1, n. 3, p. 1-7, 1938.

KOPCAK, U.; AZEVEDO, A. B. A.; MOHAMED, R. S. Extração de cafeína das sementes de guaraná (Paullinia cupana) com $\mathrm{CO}_{2}$ supercrítico e co-solventes. 2, 2004, Curitiba, In: CONGRESSO BRASILEIRO DE TERMODINÂMICA APLICADA, 15 COBEQ. Anais... Curitiba, 2004.

MARCO, G. J. A rapid method for evaluation of antioxidants. Journal of the American Oil Chemists' Society, v. 45, n. 9, p. 594-598, 1968.

MAYES, P. A. Lipídios de Importância Fisiológica. In: Harper: Bioquímica. 7 ed. São Paulo: Atheneu, 1994. p. 142-154.

MILLER, H. E. A simplified method for the evaluation of antioxidants. Journal of the American Oil Chemists' Society, v. 48, n. 2, p. 91, 1971.

MOREIRA, A. V. B. Avaliação da atividade antioxidante de sementes de mostarda (Brassica alba L.). São Paulo, 1999. Dissertação (Mestrado em Ciência dos Alimentos), Departamento de Nutrição, Universidade de São Paulo.

MOREIRA, A. V. B.; MANCINI FILHO, J. Efeito dos compostos fenólicos de especiarias sobre lípides polinsaturados. Revista Brasileira de Ciências Farmacêuticas, v. 39, n. 3, p. 130-133, 2003.

NORTHRUP, C. A sabedoria da Menopausa: criando saúde física e emocional, curando-se durante a mudança. São Paulo: Ed. Gaia, 2004.

OZER, E. O. et al. Supercritical carbon dioxide extraction of spearmint oil from mint-plant leaves. The Canadian Journal of Chemical Engineering, v. 74, n. 6, p. 920-928, 1996.

PORTER, W. L. Paradoxical behavior of antioxidants in food and biological systems. In: WILLIAN G. M., ed. Antioxidants: chemical, physiological, nutritional, and toxicological aspects. Princeton: Princeton Scientific, 1993. p. 93-122.

POVH, N. P. Obtenção do óleo essencial de camomila (Matricaria recutita L. Rauschert) por diferentes métodos: destilação por arraste a vapor, extração com solventes orgânicos e extração com $\mathrm{CO}_{2}$ supercrítico. Campinas, 2000. 217p. Tese - (Doutorado em Engenharia de Alimentos), Faculdade de Engenharia de Alimentos, Universidade Estadual de Campinas - UNICAMP.

RIBÉREAU-GAYON, P. Les composés phénoliques des végétaux. Paris: Dunod ed., 1968. p.254.

SOUSA, E. M. B. D. Construção e Utilização de um Dispositivo de Extração com Fluido Pressurizado, aplicado a Produtos Naturais. Natal, 2001. 195p. Tese - (Doutorado em Engenharia Química), 
Departamento de Engenharia Química, Universidade Federal do Rio Grande do Norte - UFRN.

SOUSA, E. M. B. D. et al. Evaluation of the Extraction Process of the Essential Oil from Cymbopogon schoenanthus with Pressurized Carbon Dioxide. Brazilian Archives of Biology and Technology, v. 48, n. spe, p. 231-236, 2005.

SOUSA, E. M. B. D. et al. Experimental results for the extraction of essential oil from Lippia sidoides Cham using pressurized carbon dioxide. Brazilian Journal of Chemical Engineering, v. 19, n. 2, p. 229-241, 2002.
SOVOVÁ, H. et al. Supercritical carbon dioxide extraction of caraway essential oil. Chemical Engineering Science, v. 49, n. 15, p. 24992505, 1994.

TURATTI, J. M. A importância dos ovos numa dieta saudável. Óleos e Grãos, v. 9, n. 59, p. 22-24, 2001.

YANISHILIEVA, N. V. I.; MARINOVA, E. M. E囚ects of antioxidants on the stability of triacylglycerols and methyl esters of fatty acids of sunflower oil. Food Chemistry, v. 54, n. 4, p. 377-382, 1995. 